\title{
Internalized homophobia in Russia
}

\author{
Alexander A. Yanykin*, Andrej D. Nasledov \\ Faculty of Psychology, Saint Petersburg State University, Saint Petersburg, Russia \\ *Corresponding author. E-mail: yanichar.666@gmail.com
}

\begin{abstract}
Objective. The goal of this study was to empirically verify that the combination of negative attitudes of LGB people towards homosexuality in general and to their own personal characteristics associated with a gay orientation has a negative impact on their self-esteem.
\end{abstract}

Design. To test this hypothesis we adapted and standardized the Russian version of the personal homonegativity scale (Mayfield, 2001). Using the adapted measure, we studied how personal homonegativity affects the self-esteem of LGB people. We explored the reliability and validity of the adapted measure with 92 gay respondents aged over 21. Confirmatory factor analysis revealed a two-scale structure - the method was proved. The modified measure includes ten statements divided into two scales: Homonegativity (internalized homophobia; Cronbach's alpha $=0.96$ ) and Acceptance of one's own homosexuality (Cronbach alpha's $=0.88$ ). The results indicated that the adapted measure was suitable for assessing internalized homonegativity among gay individuals in Russia.

Results. More than a half of the respondents (55.4\%) had a rather low level of internalized homophobia which was related to fewer neurotic symptoms and emotional discomfort in comparison with other respondents. However, a higher level of internalized homophobia in remaining respondents $(44.6 \%)$ was related to a more positive emotional acceptance of their own homosexuality and to a higher level of self-esteem.

Conclusion. The results of the analyses of the original hypothesis were confirmed only partially. Internalized homophobia of LGB people appeared to adversely affect the severity of neurotic symptoms and subjective well-being.

Keywords: homonegativity, personal homonegativity, standardization, adaptation, homophobia

\section{Introduction}

Internalized homophobia manifests itself when LGB people internalize societal attitudes towards homosexuality which results in negative self-perception, negative self-attitude and discomfort with certain aspects of their sexual orientation (Cher- 
nish, 2010). Overall, heterosexual and LGB people do not differ in terms of mental health (Huhlina, 2000). However, in Russian society, there is a widespread conviction that homosexuality is a disease which requires treatment (Chernish, 2010). We held a sociological study of the attitudes towards homosexuality that can be attributed to the measurement of homophobia in the society. According to the study conducted on a sample of 800 people, $37 \%$ of the surveyed consider homosexuality an illness (Levada-center, 2015).

As a consequence, LGB people also consider their orientation unhealthy and abnormal and believe it should be treated. In face of discrimination of LGB people in the Russian society, Russian LGB people often feel guilty and shameful about their sexual orientation. The presence of internalized homophobia (IH) may impact how they feel about themselves and contribute to low self-esteem and relationship difficulties (Chernish, 2010).

Thus, for example, Russell (2007) encouraged therapists to see IH as the result of the process of social and individual exchange and not as the result of a personal characteristic or trait. The social context of IH is also emphasized in Meyer's (2003, 2007) theory of minority stress, which provides a coherent explanation of the impact of homonegativity, or heterosexism, on LGB people, arguing that the heightened vulnerability of LGB persons originates from their exposure to stressors that are unique to their minority status. Meyer $(2003,2007)$ identified five such stressor types (experiencing prejudicial events, expectations of rejection, hiding and concealing one's sexual orientation, internalized homonegativity, and ameliorative coping processes), based on their proximity to the self. For example, the internalization of societal heterosexist attitudes is seen as a key proximal stressor, while experiences of discrimination are an example of more distal stressors. As this subjective stressor is formed in cultural contexts that are sometimes characterized by extreme stigma toward same-sex romantic, emotional, and sexual behavior, Meyer (2003) noted that IH is unique, chronic, and socially based. Inevitably, most LGB people are likely to have some level of $\mathrm{IH}$ related to their status as members of a stigmatized group.

Considering the importance of IH in mental health of LGB individuals, Western psychology offers a range of methods to assess IH (Moradi, Mohr, Worthington \& Fassinger, 2009). One measure as an attempt to improve upon prior versions is the Internalized Homonegativity Inventory (Mayfield, 2001) often used crossculturally in non-English speaking countries.

In Russia empirical studies of homonegativity are scarce. Moreover, there are no valid measures of the psychological health of the LGB people. In fact, there are only a few studies providing theoretical foundations of the development of $\mathrm{IH}$ in Russia (Voronzov, 2012). Therefore, it is necessary to develop methods to assess the level of IH among the LGB people in Russia.

Goal of the study: an empirical test of the hypothesis that there is a link between internalized homonegativity and LGB self-esteem and the attitudes toward homosexuality. Object of the study: assessment of homosexual orientation, subjective well-being, self-esteem, and social desirability. The hypothesis of the study: homonegativity will be negatively associated with the levels of subjective well-being, self-esteem and social desirability. 


\section{Method}

Objectives of the study. Exploration of the adapted measure of the IH Inventory (Mayfield, 2001); a study of the reliability of the scale and verification of factorial validity of the modified measure; development of test standards for the modified measure; a study of the relationship between internalized homonegativity, subjective well-being (emotional discomfort), self-esteem and social desirability.

Participants. The research was conducted with 92 participants (57 men and 35 women) from different cities of Russia. The average age was 29.6 for men and 27.9 for women. More than a half (72.5\%) of respondents had a bachelor's or a master's degree, $16.9 \%$ - vocational education, $10.6 \%$ - complete secondary education. In terms of income, $62.8 \%$ of respondents estimated their income as "average", $4.8 \%$ - as "low", $2.4 \%$ - as "high". $28 \%$ of all the respondents reported having seen a psychologist.

Procedure. We have created a website to facilitate access to test materials. It contained socio-demographic and measure forms for participants. The site had age restrictions (only for people over 21) and sexual orientation criteria for inclusion (only those who identified themselves as "homosexual" in the sexual orientation column). It should be pointed out that respondents were given an opportunity to define their sexual orientation themselves. If the respondent defined his/her orientation as heterosexual or bisexual, he could not continue the survey. Links to the site were posted on social networks and major online LGBT communities.

Measures. The study used the following tools:

1. A modified questionnaire to assess the level of homonegativity using Internalized Homonegativity Inventory for Gay Men (INHI (Mayfield, 2001), provided by the author for research purposes. INHI questionnaire was created in 2001. It consists of 23 items and 3 subscales: Personal Homonegativity, Gay Affirmation, Morality of Homosexuality. The distribution of IHNI scores and subscales scores were positively skewed; the inventory was constructed so that higher scores were indicative of greater internalized homonegativity. For each of the subscales coefficient alpha was .70 or greater; coefficient alpha for the entire 23-item inventory was .91. With respect to subscale correlations, all the subscales were significantly positively correlated.

2. Scale SCL 90-R (Symptom Check List-90-Revised) is aimed at the assessment of mental disorders (L. Derogatis et al., 1971). The scale contains two indices, one reflects the degree of severity of symptoms, and the other indicates the presence of symptomatic distress. This scale was chosen to explore possible anxiety, depression and obsessive disorders among the respondents related to their own attitude to themselves as well as the attitudes of their social circle. The entire array of data obtained on samples of the normal population of professionals, whose activity is connected with constant risk to life and health, as well as populations exposed to potentially traumatic events (veterans of the war in Afghanistan, liquidators of the Chernobyl disaster, refugees) was used to determine the reliability indices of the SCL- 
90-R subscales. In addition, data for two samples of psychiatric patients diagnosed with schizophrenia and somatoform disorders were included. The study used the integral indicator scale Symptomatic manifestation index (Cronbach's alpha $=0.89)$.

3. Scale of social desirability (Marlowe-Crowne Social Desirability Scale) was used to assess the degree of respondents' desire to produce a favorable impression through the demonstration of compliance to cultural norms present in society. The higher the score on this scale, the more the respondent is attempting to appear favorable even if his/her answers to morally controversial or sensitive questions are not completely honest. Accordingly, the higher the score, the more the subject endorses cultural normativity in his responses (Rajgorodskij, 2001). This scale was used in the study to assess the impact of social desirability on the respondents' answers for all methods.

4. The self-esteem scale (Rosenberg, 1972) measures overall self-esteem, assessing the level of positive and negative feelings toward oneself. The scale is one-dimensional, it does not assess multiple components that constitute self-esteem. It is based on IRT (item response theory) — the theory of latent psychological traits and psychometric concepts; that is, each test question has a different level of difficulty of responses when measuring the same construct. So according to IRT, it is supposed to consider the general effect of the answers to the test questions rather than to use different questions to assess single components. Self-esteem is understood as a holistic construct with scores ranging from low to high (A. Bodalev et al., 2000).

5. The Subjective Well-being Scale (emotional comfort), created by French psychologists (Badoux, \& Mendelsohn, 1994), was adapted by M. V. Sokolova and published in Psychodiagnostics in Russia (Sokolova, 1996)). Wellbeing embraces the following criteria: 1) external, normative criteria (the virtuous, "right" life); the person experiences well-being, if he has some socially desirable qualities; the criterion of well-being is the system of values accepted by a given culture; 2 ) life satisfaction (associated with subjective standards of "the good life" test); 3) a general understanding of happiness measured by the superiority of positive emotions over the negative. The scale consists of 17 questions related to emotional conditions, social behavior and some physical symptoms. The higher the resulting score, the lower the level of subjective well-being. Hereinafter this dimension is referred to as emotional discomfort.

6. The questionnaire also explored the following background questions: the level of identification of respondents with a homosexual identity, the number of friends among heterosexuals as well as the LGBT community; educational background, political views, income level, prior consultations of respondents with psychologists or psychiatrists concerning their homosexuality. Respondents were asked the following questions: what are your political views, what is your level of education, what is your level of income? The answers were given in free form. 
Analysis of data was performed in the following sequence:

1. An analysis of the frequency distribution for each statement was explored to identify items that cannot be used in the study sample due to a low discriminative value.

2. Exploratory factor analysis (method: Principal components) to combine the items into factors (scales).

3. Confirmatory factor analysis to test hypotheses about the factorial validity of the identified constructs.

4. Scale reliability analysis of the internal consistency of the items that make up the adapted measure. The Cronbach's alpha method was used. In addition to the calculation of Cronbach's alpha $(\alpha)$ for each scale, this ratio was calculated for the scale if each item deleted. This showed the potential improvement in the scale reliability if particular items were removed.

5. Analysis of the relationship between homonegativity scales and psychological measures (i.e. subjective well-being, anxiety, symptoms of depression and self-esteem) via correlation analysis and SEM (structural equation modeling).

6. Development of test standards for homonegativity scales.

To perform an analysis of data, we used IBM SPSS Statistics and AMOS software (St. Petersburg State University Department of Psychology).

\section{Results}

When adapting the IH measure (Mayfield, 2001), the method was translated by three different specialists: a psychologist, a linguist, and a native speaker. The three translations were used to compile the stimulus material of 70 statements. When the identical content was discarded (62 out of 70 items remained), we assessed the suitability of the questionnaire to determine the discriminatory power of each statement. Discriminatory power is understood as the number of similar responses, expressed as a percentage. The statement was considered suitable if the proportion of positive responses ranged from 10 to $90 \%$. Thus, low discriminatory power was found in 13 statements. As a result 59 statements remained.

To verify the adequacy of the Russian version and sustainability of the original factor structure, the data obtained during the test were subjected to exploratory factor analysis (method: Principal components). A 3-factor solution provided the best fit. The first factor (18 items) included statements which captured: a) negative emotions experienced by homosexuals towards their orientation (e.g., shame, depression); b) negative attitudes toward their orientation (e.g., hatred towards the sexual orientation and a need to control feelings of same-sex people). The second factor (6 items) included statements of homosexuals who described their orientation as an important and positive part of themselves with the belief that being gay is normal. The third factor (4 items) included statements which reflected negative attitudes toward same-sex relationships from a moral perspective.

If the factor analysis confirmed the presence of three factors, factorial validity of the method scales was assessed using confirmatory factor analysis as a special 
case of SEM methodology. The results of an exploratory factor analysis (3 factors, 28 items) were used as an a priori hypothetical structure of the scales.

When applying SEM, two conditions of applicability of the method were tested: sufficiency of the sample size and multivariate normality of the distribution of variables. The sample is considered to be an acceptable number (N) if $\mathrm{N}>5 \mathrm{~T}$ where $\mathrm{T}$ is the number of estimated parameters (Nasledov, 2013). In our case, $\mathrm{N}=92$ and $\mathrm{T}=23$ (i.e., for our model, the number of people was smaller than the recommended number). In this case, the model can be trusted only if it is consistent with the original data on the computed indexes of model fit. To examine the multivariate distribution and normality of variables, multivariate kurtosis and the Critical Ratio (C.R.) were applied. The calculations were performed with the AMOS software. Multivariate normality is considered fulfilled if the C.R. slightly exceeds 5 (Nasledov, 2013). In our case, the C.R. $=18.43$, indicating a significant deviation in the multivariate distribution of variables; thus, the standard SEM analysis methods were deemed unacceptable. However, the AMOS software offers a parameter estimation method which met our needs - the Asymptotically distribution-free method allows for a significant deviation from the multivariate normality. The final model of the method is presented below, see Figure 1 .

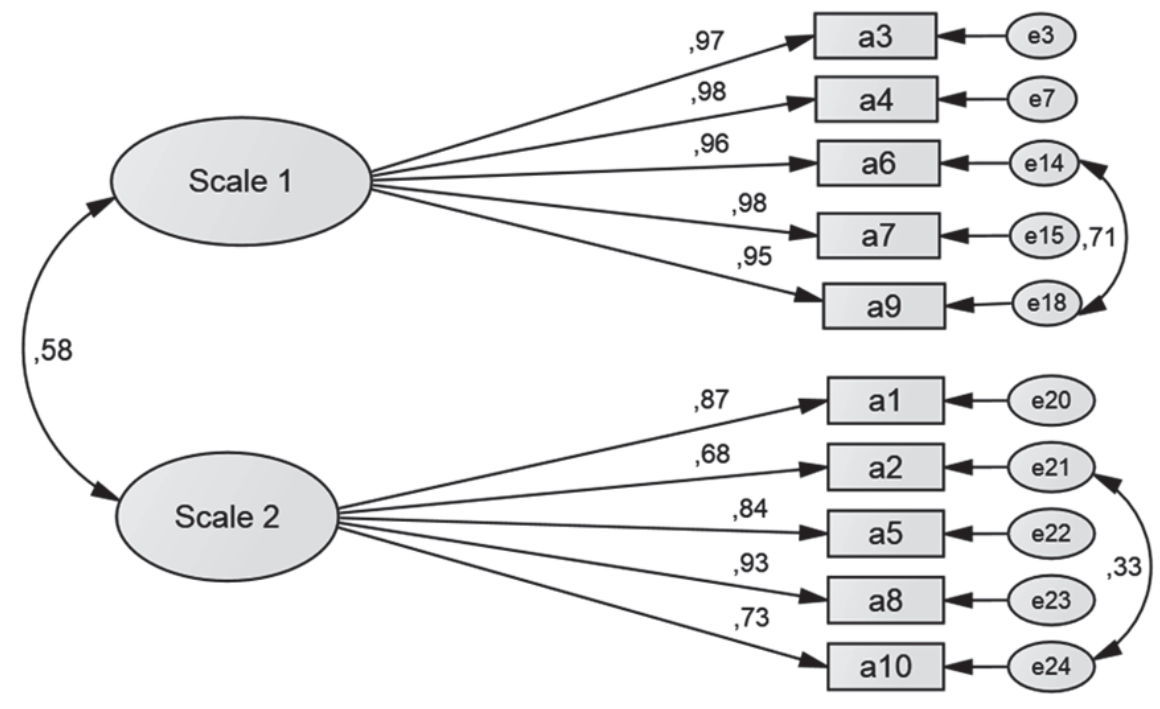

$\mathrm{CMIN}=33.984 ; \mathrm{df}=32 ; \mathrm{p}=0.372 ; \mathrm{GFI}=0.953 ; \mathrm{CFI}=0.993 ; \mathrm{RMSEA}=0.026 ;$ Pclose $=0.689$

Figure 1. The final model of the homonegativity diagnostic method

As the diagram in Figure 1 shows, the final model of the homonegativity diagnostic method included only two scales. The model is considered consistent with the original data on fit indexes (Nasledov, 2013); the main ones are listed at the bottom of the diagram. They indicate very high level of consistency with the original data; all fit indexes are significantly better than the recommended values. Equally important for the compliance of the models with the original data is the statistical significance of the estimated parameters: regression coefficients, variances of latent variables, and covariances. All the estimated parameters for the final model are statistically significant $(\mathrm{p}<0.01)$. The statistical significance of the latent variables in 
scales 1 and 2 shows that the variance is reliably different from zero (i.e., they have sufficient discriminatory power).

Scale 1 ("Personal homonegativity") included statements 3, 4, 6, 7, 9 of the original scale (see Appendix). Scale 2 ("Acceptance of homosexuality") included statements $1,2,5,8,10$ of the original scale list (see Appendix).

Further, the scale reliability was tested for internal consistency by Cronbach's alpha method: for the entire sample and separately for men and women. We assumed that none of the scale items were "superfluous" as its reliability decreased once an item was discarded. Let us examine the Cronbach's alphas: Scale 1: $\alpha=0.96$ (for men: $\alpha=0.96$, for women: $\alpha=0.95$ ); scale 2 : $\alpha=0.88$ (for men: $\alpha=0.87$, for women: $a=0.90$ ). The results suggest high reliability of the scales on the internal consistency of items.

Further, the relationship of homonegativity scales with socio-demographic indicators was examined: age, sex, political views, prior consultations of respondents with psychologists or psychiatrists concerning their homosexuality, education. The correlation analysis (Spearman correlation) showed no statistically significant relationships between age and homonegativity scales. The relationship of other indicators to IH was analyzed using multivariate analysis of variance (dependent variables were the two homonegativity subscales; the explored factors: gender, political views, consultations with a psychologist, education, income). We examined the main effects and all two-factor interactions. There were no significant effects on homonegativity scales by sex, political opinions, consultations with a psychologist (yes/no), education, and material well-being.

Table 1. Pearson correlations $(r)$ of the variables $(\mathrm{N}=92)$

\begin{tabular}{lccccccc}
\hline & & Scale 1 & Scale 2 & $\mathrm{R}$ & SPI & SBS & SDS \\
\hline \multirow{2}{*}{ Scale 1 } & $\mathrm{R}$ & 1 & $.504^{* *}$ & $.466^{* *}$ & .199 & $.275^{* *}$ & .001 \\
& $\mathrm{P}$ & & .000 & .000 & .057 & .008 & .990 \\
\multirow{3}{*}{ Scale 2 } & $\mathrm{R}$ & $.504^{* *}$ & 1 & $.229^{*}$ & -.072 & .103 & .108 \\
& $\mathrm{P}$ & .000 & & .028 & .495 & .329 & .308 \\
$\mathrm{~N}$ & $\mathrm{R}$ & $.466^{* *}$ & $.229^{*}$ & 1 & $.446^{* *}$ & $.462^{* *}$ & -.138 \\
$\mathrm{R}$ & $\mathrm{P}$ & .000 & .028 & & .000 & .000 & .191 \\
& $\mathrm{R}$ & .199 & -.072 & $.446^{* *}$ & 1 & $.596^{* *}$ & -.096 \\
\multirow{2}{*}{$\mathrm{SPI}$} & $\mathrm{P}$ & .057 & .495 & .000 & & .000 & .365 \\
& $\mathrm{R}$ & $.275^{* *}$ & .103 & $.462^{* *}$ & $.596^{* *}$ & 1 & -.179 \\
\multirow{2}{*}{$\mathrm{SBS}$} & $\mathrm{P}$ & .008 & .329 & .000 & .000 & & .088 \\
& $\mathrm{R}$ & .001 & .108 & -.138 & -.096 & -.179 & 1 \\
\multirow{2}{*}{ SDS } & $\mathrm{p}$ & .990 & .308 & .191 & .365 & .088 & \\
\hline
\end{tabular}

${ }^{* *}$. Correlation is significant at the 0.01 level (2-tailed).

${ }^{*}$. Correlation is significant at the 0.05 level (2-tailed).

Scale 1 - Personal homonegativity; Scale 2 - Acceptance of their homosexuality; R - Level of selfesteem; SPI - Emotional discomfort; SBS - Symptomatic manifestation index on SCL-90; SDS Marlowe-Crowne Social Desirability Scale 
Analysis of the relationship between homonegativity scales and psychological measures was conducted by correlation analysis with indicators taken from a number of tests (social desirability by Crowne Marlowe, the scale of subjective wellbeing adapted by Sokolova (emotional discomfort), self-esteem scale of Rosenberg, the scale of positive responses on SCL-90). Correlations between these indicators are shown in Table 1.

To test direct and indirect effects the structural model was tested, supposing that Scale 1 (Personal homonegativity) affects Level of self-esteem, Symptomatic manifestation index on the SCL-90 and Emotional discomfort. The final structural model (SEM) is presented below, in Figure 2.

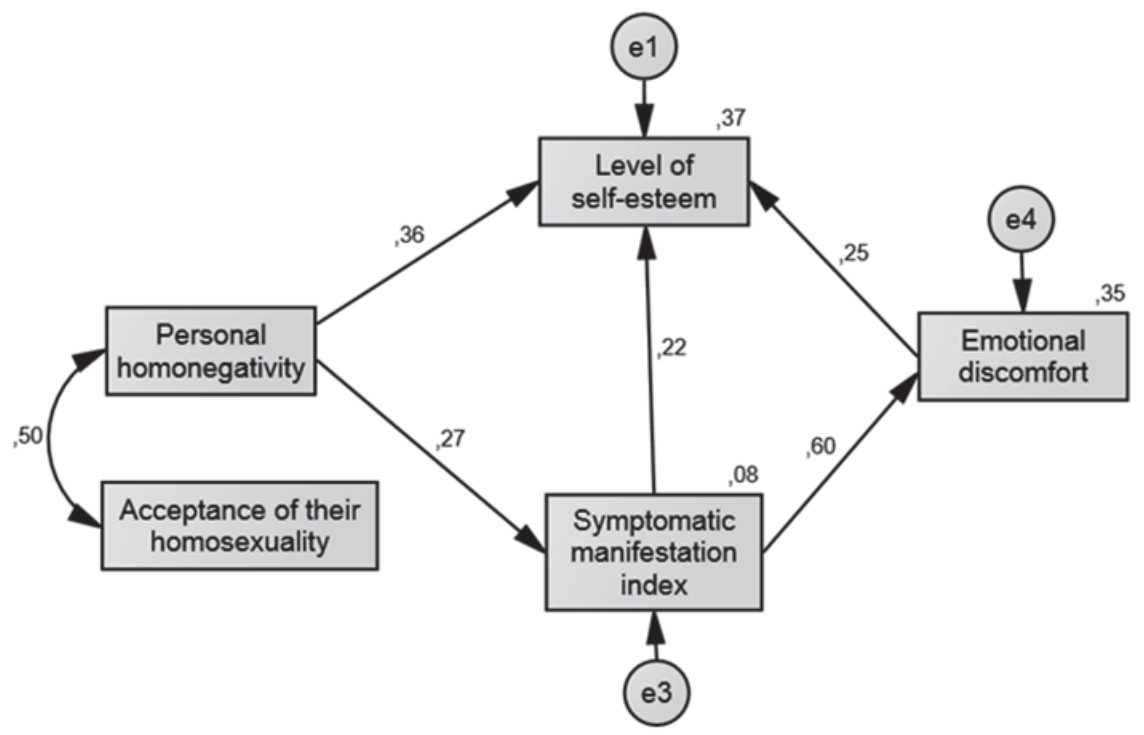

$\mathrm{CMIN}=5,222 ; \mathrm{df}=4 ; \mathrm{p}=0.265 ; \mathrm{GFI}=0.978 ; \mathrm{CFI}=0.989 ; \mathrm{RMSEA}=0.058 ;$ Pclose $=0.375$

Figure 2. Interconnection scales as diagnostic methods of homonegativity with indicators of the self-attitudes

The number of parameters to be estimated $\mathrm{T}=11$, therefore, the sample size $(\mathrm{N}=92)$ is sufficient as it is more than 5 times the T. Multivariate normality was considered fulfilled: the Critical Ratio for Multivariate kurtosis C.R. $=2.65$ (less than 5). The model is considered consistent with the original data on fit indexes. All of the estimated parameters for the final model (regression coefficients, variances of latent variables, and covariances) were statistically significant $(\mathrm{p}<0.05)$.

In accordance with the model (Figure 2) Scale 1 (Personal homonegativity) relates most strongly to level of self-esteem: the total effect is 0.459 (direct effect 0.359 plus indirect effect $=0.100$ ). Personal homonegativity relates to the Symptom checkllist index (direct effect 0,275) to a lesser extent and to Emotional distress (indirect effect 0,164 ) - to the least.

New standardization of the diagnostic method for homonegativity scales was performed on a sample of $\mathrm{N}=92$. The algorithm of nonlinear standardization was used (Nasledov, Slavinskaya, Dvoretskaya, 2015). Results of the standardization are presented in Table 2. 
Table 2. Test norms of modified scales (Mayfield) (table of conversion from raw scores to stan)

\begin{tabular}{ccccccccc}
\hline \multicolumn{7}{c}{ Scale 1 ("Personal homonegativity") } \\
\hline Stan & - & - & 5 & 6 & 7 & 8 & 9 & 10 \\
$\%$ & - & - & 55.43 & 16.30 & 11.96 & 9.78 & 4.35 & 2.17 \\
$\begin{array}{c}\text { Raw } \\
\text { scores }\end{array}$ & - & - & 5 & $6-10$ & $11-16$ & $17-22$ & $23-24$ & $>24$ \\
\hline \multicolumn{7}{c}{ Scale 2 (“Acceptance of their homosexuality") } \\
\hline $\begin{array}{c}\text { Stan } \\
\%\end{array}$ & 3 & 4 & 5 & 6 & 7 & 8 & 9 & 10 \\
$\begin{array}{c}\text { Raw } \\
\text { scores }\end{array}$ & $5-7$ & $8-10$ & $11-14$ & $15-18$ & $19-23$ & $24-26$ & 27 & $>27$ \\
\hline
\end{tabular}

It should be pointed out that on Scale 1 ("Personal homonegativity"), $55.43 \%$ of the respondents have a minimum possible value of 5 . This, in fact, means an almost complete denial of Personal homonegativity. In this regard, this part of the sample (Scale 1=5) was compared with all the others who reported Personal homonegativity (value Scale $1>5$ ). Results of the comparison are presented in Table 3.

Table 3. Comparison of polar results on the "Personal homonegativity" scale

\begin{tabular}{cccccccc}
\hline & Scale 1: & $\mathbf{N}$ & Mean & Std. Deviation & $\mathbf{t}$ & $\mathbf{d f}$ & Sig. (2-tailed) \\
\hline \multirow{2}{*}{ Scale 2} & $=5$ & 51 & 12.6667 & 6.31401 & & & \\
& $>5$ & 41 & 18.5610 & 6.17677 & -4.494 & 90 & .000 \\
\multirow{2}{*}{$\mathrm{R}$} & $=5$ & 51 & 16.569 & 4.5880 & & & \\
& $>5$ & 41 & 19.610 & 4.4659 & -3.198 & 90 & .002 \\
\multirow{2}{*}{ SPI } & $=5$ & 51 & 34.039 & 23.5525 & & & \\
& $>5$ & 41 & 47.146 & 18.7797 & -2.898 & 90 & .005 \\
\multirow{2}{*}{ SBS } & $=5$ & 51 & 57.863 & 17.1208 & & & \\
& $>5$ & 41 & 66.268 & 12.7456 & -2.614 & 90 & .010 \\
\hline
\end{tabular}

Scale 1 - Personal homonegativity; Scale 2 - Acceptance of their homosexuality; R - Level of selfesteem; SPI - Emotional discomfort; SBS - Symptomatic manifestation index on SCL-90.

The results of the comparisons (Table 3) confirm the results presented earlier: the presence of "Personal homonegativity" is statistically and significantly associated with higher values on the variables: Acceptance of their homosexuality, Level of self-esteem, Emotional discomfort and Symptomatic manifestation index on the SCL-90. 


\section{Discussion}

At the beginning 59 statements with sufficient discriminatory power were selected. Then the method of factor analysis (principle component analysis) was applied. The results of factor analysis were of interest since the selected factors coincided in meaning to the subscales in the original IH. However, the CFA revealed a twofactor structure of the adapted questionnaire for the Russian sample. Dispersion of factors (scales), which were statistically significantly different from $0(\mathrm{p}<0.01)$, suggested the existence of these two constructs and their differentiating ability. The absence of "intersections" of constructs was also evident in the factorial validity of the scales - each statement (question) of the questionnaire statistically and significantly associated with only one factor, the other factor is indistinguishable from 0 . This convinced us of the sufficiency of latent constructs selected by these scales. These scales had high reliability in the internal consistency of statements $(\alpha>0.9)$.

Scale 1 "Personal homonegativity (Internalized homophobia)" included 5 statements form the original measure (see Appendix), which characterize: a) negative emotions experienced by homosexuals towards their orientation (e.g. shame, depression ); b) negative attitude to their orientation (e.g. hatred towards the sexual orientation, need to control feelings of same-sex people).

Scale 2 "Acceptance of their homosexuality" included 5 statements of the final measure (see Appendix), which assessed the level of self-acceptance by homosexuals who perceived their orientation to be an important and positive part of themselves and believed that being homosexual is normal.

Correlations of scales 1 and 2 with the Marlowe-Crowne Social Desirability Scale were close to zero, which testified to the sincerity of respondents' answers.

It should be said that $55.43 \%$ of the sample had a minimum possible value on the scale of homonegativity, i.e. more than half of the respondents denied that they had any IH. These respondents also reported lower levels of neurotic symptoms according to the Symptom Check List-90-Revised and higher levels of subjective well-being and emotional discomfort. However, it was a quite unexpected result the that self-esteem was lower in this group as well as the indicator of self-estimation. It may be that this group of respondents in the beginning of understanding of their orientation. It can be illustrated by their more negative emotional estimation of their homosexual orientation (Scale 2).

The rest of the respondents (45\%) reported the presence of $\mathrm{IH}$ to a greater or lesser extent, negative attitudes to their own orientation (according to Scale of Homonegativity) and negative emotions connected with IH. As it was hypothesized, they had higher levels of neurotic symptoms, and lower level of subjective wellbeing and emotional comfort. At the same time they had a higher level of emotional acceptance and self-esteem in spite of their marked homonegativity.

Structural equation modeling (SEM) was used to find out which of the effects of the reciprocal influence of the studied constructs are direct and which are indirect. The structural model (SEM) was based on the assumption that homonegativity and acceptance of one's homosexuality is associated with level of self-esteem, subjective distress and the index of severity of psychological symptoms. The final model (Fig. 2) confirmed several important facts. First of all, paradoxically, personal homonegativity and acceptance of one's own homosexuality were correlated positively: the higher the level of $\mathrm{IH}$, the higher the positive emotional evaluation 
of their own homosexuality. Secondly, emotional acceptance of own homosexuality related directly to homonegativity, and had no direct influence on the other studied constructs: apparently, this effect was mediated by indirect homonegativity. Thirdly, homonegativity affected most strongly the level of self-esteem (directly and indirectly through other constructs), and again, paradoxically, the higher the level of IH the higher the level of self-esteem. The relationship of IH to neurotic symptoms appeared somewhat weaker: the higher the level of homonegativity, the higher the neurotic symptoms. And finally, an indirect effect of IH on subjective distress was weak and mediated by neurotic symptoms which, however, was also expected: the higher the level of homonegativity, the lower the feeling of emotional well-being. Fourth, neurotic symptoms and emotional discomfort affected directly and positively the level of self-esteem.

Thus, the structural model confirmed only partly the assumptions about the negative impact of IH on the psychological status of LGB people: this influence was shown in relation to neurotic symptoms and, with their increase, indirectly - in relation to subjective feelings of well-being (emotional comfort). Self-esteem was the main dependent variable of the model, a positive feeling about oneself. Paradoxically, in contrast to initial assumptions, self-esteem was positively related to $\mathrm{IH}$, which, as expected, was associated with increased neurotic symptoms as well as a subjective sense of emotional distress. But the latter, again, paradoxically, increased self-esteem.

We can try to explain the observed contradiction between IH and self-esteem with the well-known theory of cognitive dissonance of Festinger (Heckhausen, 1986). The basic postulate of this theory is the human desire for harmony, coherence and congruence of cognitive representations of the external world and themselves. This theory considers the relationship between the content of cognitive elements and motivational effects arising from the tendency for coherence if two elements are in contradiction (Heckhausen, 1986). It is obvious that IH and the neurotic symptoms associated with it, on the one hand, and positive emotional evaluation of one's own homosexuality, on the other hand, are in a dissonant relationship. According to the research it can be assumed that the reduction of cognitive dissonance of LGB people is as follows: the higher the level of external IH, the harder these people are trying to reduce the negative, strengthening the emotional appeal of their homosexual orientation and reduce negative feelings about themselves, raising self-esteem and self-respect. An alternative approach to the reduction of cognitive dissonance shows that a majority of the respondents (55.4\%) reported no internalization of external homophobia, thus eliminating the need to report positive aspects of their homosexuality and self-esteem in general, resulting in lower neurotic symptoms and feelings of emotional discomfort.

\section{Conclusion}

It is desirable to clarify the construct validity of the modified scales of diagnostic methods of homonegativity with a wider set of external criteria and psychological constructs and on a bigger sample. There are reasons to believe that the meaningful interpretation of the scales will be more relevant once the method is put into practice. 
The finding of the non-trivial positive link between IH and the attractiveness of one's own homosexuality and self-esteem require further investigation. For this purpose it is recommended that external criteria and a broader set of psychological constructs in a larger group of respondents are used.

A limitation of this study is that the affiliation of respondents to LGB people was determined by self-report and the constructs were based mainly on self-assessment.

\section{References}

Bodalev, A.A., Stolin, V.V., \& Avanesov, V.S. (2000). Obshhaja psihodiagnostika [General psychology]. Saint Petersburg, Russia: Rech.

Chernysh, K. (2010). Gomofobiya, samootnoshenie i kvir-identichnost [Homophobia, self-attitude and queer identity]. In V. Sozaev (Ed.), Vozmozhen li "kvir" po-russki? LGBTK issledovanija [Is "Russian queer” possible? LGBTQ studies]. (pp. 134-136). Saint Petersburg, Russia: Intan.

Gonsiorek, J.C. (1995). Gay male identities: Concepts and issues. In A. R. D’Augelli \& C. J. Patterson (Eds.), Lesbian, gay, and bisexual identities over the lifespan: Psychological perspectives. (pp. 25-37). New York: Oxford University Press.

Huhlina, V.V. (2000). Nekommercheskij sektor kak socialnyj institut: Na primere socialnogo obsluzhivanija naselenija [Non-profit sector as a social institution: At the example of social services for the population]. (PhD dissertation). Moscow State University of Service, Moscow.

Levada Center (2015). Homophobia. Retrieved from http://www.levada.ru/en/2015/06/10/homophobia

Mayfield, W. (2001). The development of an Internalized Homonegativity Inventory for gay men. Journal of Homosexuality, 41(2), 53-76. doi: 10.1300/J082v41n02_04

Meyer, I.H. (2007). Prejudice and discrimination as social stressors. In: I.H. Meyer \& M.E. Northridge (Eds.), The health of sexual minorities. (pp. 242-267). New York, NY: Springer. doi: 10.1007/978-0-387-31334-4_10

Meyer, I.H. (2003). Prejudice, social stress, and mental health in lesbian, gay, and bisexual populations: Conceptual issues and research evidence. Psychological Bulletin, 129(5), 674-697.

Moradi, B., Mohr, J.J., Worthington, R. L., \& Fassinger, R. E. (2009). Counseling psychology research on sexual (orientation) minority issues: Conceptual and methodological challenges and opportunities. Journal of Counseling Psychology, 56, 5-22. doi: 10.1037/a0014572

Nasledov, A.D. (2013). IBM SPSS Statistics 20 i AMOS: professionalnyy statisticheskiy analiz dan$n y k h$ [IBM SPSS Statistics 20 and AMOS: Professional statistical analysis of data]. Saint Petersburg, Russia: Piter.

Nasledov A.D., Slavinskaya, I.S., \& Dvoretskaya, M.Y. (2015). Razrabotka metodiki diagnostiki nravstvennykh orientatsiy [Development of methods for diagnosing moral orientations. Sovremennye issledovaniya sotsialnykh problem [Contemporary Research of Social Issues], 1(45), 3-26.

Rajgorodskij, D.J. (2001). Metodika diagnostiki samoocenki motivacii odobrenija (Shkala lzhi) [The methodology for diagnosing self-assessment of motivation for approval (Scale of Lies)]. In Prakticheskaja psihodiagnostika. Metodiki i testy. Uchebnoe posobie [Practical psychodiagnosis. Methods and tests. Tutorial]. (pp. 635-636). Samara, Russia: BAHRAH-M.

Rosenberg, M. (1972). Self-esteem Scale. In J. P. Robinson \& P. R. Shaver (Eds.), Measures of social psychological attitudes (pp. 98-101). Ann Arbor: Institute for Social Research. 
Russell, G.M. (2007). Internalized homophobia: Lessons from the Mobius strip. In C. Brown \& T. Augusta-Scott (Eds.), Narrative therapy: Making meaning, making lives (pp. 151-173). Thousand Oaks, CA: Sage. doi: 10.4135/9781452225869.n8

Sokolova, M.V. (1996). Shkala subjektivnogo blagopoluchija [Scale of subjective well-being]. Jaroslavl, Russia: Psikhodiagnostika.

Tabarina, N.V. (2001). Praktikum po psikhologii posttravmaticheskogo stressa [Workshop on psychology of post-traumatic stress]. Saint Petersburg, Russia: Piter.

Vorontsov, D.V. (2012). Kvir-teoriya: perspektivy psikhologicheskogo analiza seksualnosti. [Queer theory: The prospects for the psychological analysis of sexuality]. Voprosy psihologii [Issues in Psychology], 2, 153-162.

Original manuscript received February 22, 2017

Revised manuscript accepted May 07, 2017 First published online June 30, 2017 


\section{Appendix}

Standardized diagnostic method of homonegativity of Mayfield (in modification of A.A. Yanykin, A.D. Nasledov)

Instructions: please answer the following questions by checking the response number that best reflects your opinion.

$$
\begin{aligned}
& 1 \text { - Strongly disagree } \\
& 2 \text { - Rather disagree } \\
& 3 \text { - Slightly disagree } \\
& 4 \text { - Slightly agree } \\
& 5 \text { - Rather agree } \\
& 6 \text { - Strongly agree }
\end{aligned}
$$

The text of the questionnaire (the male version)

\begin{tabular}{|l|l|}
\hline 1. I am grateful for the sexual orientation that I have.(6) & 123456 \\
\hline 2. I'm proud that I'm a LGB person.(21) & 123456 \\
\hline 3. When I think of my homosexual orientation I get upset.(3) & 123456 \\
\hline 4. I feel sometimes that homosexuality is cause for shame.(5) & 123456 \\
\hline 5. I am grateful to my fate for my orientation.(6) & 123456 \\
\hline 6. It upsets me sometimes that I'm sexually attracted to men.(7) & 123456 \\
\hline 7. When I think about my homosexuality I feel dejected.(3) & 123456 \\
\hline 8. I accept my homosexuality.(1) & 123456 \\
\hline 9. I'm ashamed of my homosexual orientation.(5) & 123456 \\
\hline 10. I treat my homosexuality as a gift.(9) & 123456 \\
\hline
\end{tabular}

Assertion numbers from the original techniques Mayfield (2001) are in parentheses.

\section{Processing and interpretation of results}

For each scale, the "raw score" was calculated as a sum of constituent items:

Scale "Personal homonegativity", statements: 3,4,6,7,9.

The subscale includes: (a) the negative emotions that LGB people have for their own orientation (e.g., shame, depression, and shame) and (b) negative attitude to their own orientation (e.g., anger on their sexual orientation, the desire to control their feelings towards people of the same sex).

Scale "Acceptance of own homosexuality", statements: 1,2,5,8,10.

This subscale consists of 5 items that measure the extent to which LGB people feel that their orientation is an important and positive part of themselves and that being a LGB person is normal.

The "raw scores" are recommended to use for research purposes. Standard scores on a scale of "Stan" should be used to interpret the results of individual testing. The translation of raw scores to the "Stan" is carried out using Table 3. 